\title{
Fludarabine, High-Dose Cytarabine and Idarubicin-Based Induction May Overcome the Negative Prognostic Impact of FLT3-ITD in NPM1 Mutated AML, Irrespectively of FLT3-ITD Allelic Burden
}

\author{
Paola Minetto ${ }^{1,2, *(\mathbb{D})}$, Anna Candoni ${ }^{3}\left[\mathbb{D}^{-}\right.$, Fabio Guolo ${ }^{1,2, *} \mathbb{C}$, Marino Clavio ${ }^{1,2}$, Maria Elena Zannier ${ }^{3}$, \\ Maurizio Miglino ${ }^{1,2}$, Maria Vittoria Dubbini ${ }^{3}$, Enrico Carminati ${ }^{1,2}$, Anna Sicuranza ${ }^{4}$, Sara Ciofini ${ }^{4}$, \\ Nicoletta Colombo ${ }^{2}$, Girolamo Pugliese ${ }^{1,2}$, Riccardo Marcolin ${ }^{1}$, Adele Santoni ${ }^{4}$, Filippo Ballerini ${ }^{1,2}$,

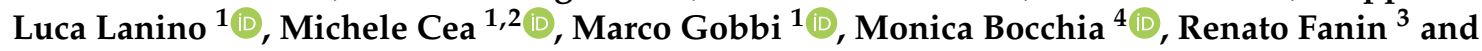 \\ Roberto Massimo Lemoli ${ }^{1,2}$
}

1 Clinic of Hematology, Department of Internal Medicine (DiMI), University of Genoa, 16132 Genova, Italy; claviom@unige.it (M.C.); maurizio.miglino@hsanmartino.it (M.M.); ematlab@unige.it (E.C.); ematologia@unige.it (G.P.); s4582953@studenti.unige.it (R.M.); filippo.ballerini@hsanmartino.it (F.B.); s3898392@studenti.unige.it (L.L.); michele.cea@unige.it (M.C.); gobbi@unige.it (M.G.); roberto.lemoli@unige.it (R.M.L.)

2 IRCCS-Ospedale Policlinico San Martino, 16132 Genova, Italy; nicoletta.colombo@hsanmartino.it

3 Division of Hematology and Bone Marrow Transplantation, Azienda Sanitaria Universitaria Integrata di Udine, 33100 Udine, Italy; anna.candoni@asufc.sanita.fvg.it (A.C.); mariaelena.zannier@asufc.sanita.fvg.it (M.E.Z.); mariavittoria.dubbini@asufc.sanita.fvg.it (M.V.D.); renato.fanin@asuiud.sanita.fvg.it (R.F.)

check for updates

Citation: Minetto, P.; Candoni, A.; Guolo, F.; Clavio, M.; Zannier, M.E.; Miglino, M.; Dubbini, M.V.; Carminati, E.; Sicuranza, A.; Ciofini, S.; et al. Fludarabine, High-Dose Cytarabine and Idarubicin-Based Induction May Overcome the Negative Prognostic Impact of FLT3ITD in NPM1 Mutated AML, Irrespectively of FLT3-ITD Allelic Burden. Cancers 2021, 13, 34 .

https://dx.doi.org/

10.3390/cancers 13010034

Received: 21 November 2020 Accepted: 21 December 2020 Published: 24 December 2020

Publisher's Note: MDPI stays neutral with regard to jurisdictional claims in published maps and institutional affiliations.

Copyright: () 2020 by the authors. Licensee MDPI, Basel, Switzerland. This article is an open access article distributed under the terms and conditions of the Creative Commons Attribution (CC BY) license (https:/ / creativecommons.org/ licenses/by/4.0/).
4 Hematology Unit, University of Siena, Azienda Ospedaliera Universitaria, 53100 Siena, Italy; sicuranza4@unisi.it (A.S.); sara.ciofini@ao-siena.toscana.it (S.C.); adele.santoni@student.unisi.it (A.S.); monica.bocchia@unisi.it (M.B.)

* Correspondence: paola.minetto@hsanmartino.it (P.M.); fabio.guolo@unige.it (F.G.); Tel.: +39-10-555-4329 (P.M.); +39-10-555-4491 (F.G.)

Simple Summary: The prognostic relevance of molecular aberrations in acute myeloid leukemia (AML) has been prevalently tested in patients receiving conventional 3+7 induction. Recently, there has been a renewed interest in intensified inductions, but very few data are available on the impact of the most frequent genetic alterations with these alternative treatments. We analyzed a large multicentric cohort of younger AML patients harboring NPM1 and FLT3-ITD mutations receiving an intensified fludarabine-containing regimen (FLAI). Our data suggest that in NPM1 mut patients, FLAI may overcome the prognostic influence of co-mutated FLT3-ITD. The increased efficacy of this treatment seems to reduce the need for early consolidation with allogeneic transplant in doublemutated patients. Our data strongly support FLAI as an ideal backbone for combination with innovative targeted drugs, in order to further improve patients' outcome.

Abstract: The mutations of NPM1 and FLT3-ITD represent the most frequent genetic aberration in acute myeloid leukemia. Indeed, the presence of an NPM1 mutation reduces the negative prognostic impact of FLT3-ITD in patients treated with conventional " $3+7$ " induction. However, little information is available on their prognostic role with intensified regimens. Here, we investigated the efficacy of a fludarabine, high-dose cytarabine and idarubicin induction (FLAI) in 149 consecutive fit AML patients (median age 52) carrying the NPM1 and/or FLT3-ITD mutation, treated from 2008 to 2018. One-hundred-and-twenty-nine patients achieved CR (86.6\%). After a median follow up of 68 months, 3-year overall survival was 58.6\%. Multivariate analysis disclosed that both NPM1mut $(p<0.05)$ and ELN 2017 risk score $(p<0.05)$ were significant predictors of survival. NPM1-mutated patients had a favorable outcome, with no significant differences between patients with or without concomitant FLT3-ITD ( $p=0.372)$, irrespective of FLT3-ITD allelic burden. Moreover, in landmark analysis, performing allogeneic transplantation (HSCT) in first CR proved to be beneficial only in ELN 2017 high-risk patients. Our data indicate that FLAI exerts a strong anti-leukemic effect in younger AML patients with NPM1mut and question the role of HSCT in 1st CR in NPM1mut patients with concomitant FLT3-ITD. 
Keywords: acute myeloid leukemia; NPM1; FLT3-ITD; intensified induction; minimal residual disease assessment; allogeneic stem cell transplantation

\section{Introduction}

An increasing number of genetic and epigenetic abnormalities have been shown to display prognostic value in acute myeloid leukemia (AML) [1-3]. The European Leukemia Net (ELN) implemented the risk stratification at diagnosis by integrating cytogenetics and molecular data and strongly recommended NPM1 and FLT3 mutational status assessment [4]. The presence of NPM1 mutation (NPM1 mut) reduces the negative prognostic impact of FLT3-ITD, which is also modulated by FLT3-ITD/wild-type allelic ratio [5,6]. However, most information on the prognostic impact of NPM1 and/or FLT3 mutations comes from trials with daunorubicin and cytarabine (" $3+7$ ") induction [7-9]. The recent randomized trial by Stone et al. showed that the addition of midostaurin to conventional 3+7 induction improved the outcome of FLT3-ITD-positive AML patients [10]. Furthermore, the benefit of adding gemtuzumab ozogamicin (GO) to 3+7 regimen in low-intermediaterisk patients has been confirmed by a recent randomized French trial [11]. High-dose cytarabine-containing regimens (ICE, FLAI MRC, CLIA, CLAG) have been reported to achieve high complete remission (CR) rate and favorable outcome in younger AML patients, but information on their activity on specific molecular subsets is still incomplete and the role of allogeneic stem cell transplantation (HSCT) in first complete remission in this therapeutic scenario has not been defined to date [12-19]. We have already reported that, following a fludarabine-containing intensified induction, NPM1 mutation was associated with a very high CR rate and good disease-free survival (DFS) and overall survival (OS). Moreover, the presence of FLT3-ITD did not negatively affect prognosis in the whole cohort of patients and HSCT in first CR did not lead to an improved outcome of non-high-risk patients [14]. However, the small size of the studied cohort did not allow to disclose which molecular subsets of patients (NPM1 mut, FLT3-ITD or concomitant aberrations) may benefit the most from our intensified approach [14]. In this paper, we analyzed the impact of the two most frequent molecular aberrations in a larger cohort of AML patients, homogeneously treated with an intensified induction and consolidation therapy in three Italian hematology centers. Moreover, we evaluated the impact of HSCT in this setting

\section{Methods}

\subsection{Study Design}

This retrospective study involved, 149 patients (median age 52; range 18-65), treated with the same intensified fludarabine-containing induction between January 2008 and January 2018 in three Italian Hematology Centers, who tested positive for the NPM1 mutation or FLT3-ITD mutation or both. Written informed consent for biological sample analysis and for data collection was obtained for each patient enrolled. The study was conducted according to the Declaration of Helsinki.

\subsection{Diagnostic Workup and Molecular Analysis and Risk Assessment}

Conventional cytogenetic analysis with q-banding was performed and cytogenetic abnormalities were graded according to Medical Research Council Criteria [3]. Molecular work-up was performed as per European Leukemia Net recommendation, evaluation of FLT3-ITD allelic burden, TP53, RUNX1, ASXL-1 was performed on stored samples, if not performed at diagnosis, in order to retrospectively apply European LeukemiaNet 2017 (ELN 2017) for risk definition in all patients [4]. MRD evaluation by real-time PCR for NPM1 was performed as previously described. [5,6,20-23]. Further details on cytogenetic and molecular analysis are provided in Appendix A. 


\subsection{Treatment Schedule}

Treatment included two induction courses. Induction one consisted of fludarabine $30 \mathrm{mg} / \mathrm{sqm}$, followed $4 \mathrm{~h}$ later by high-dose cytarabine ( $2000 \mathrm{mg} / \mathrm{sqm})$ infused in $4 \mathrm{~h}$ on days 1 to 5 , whereas idarubicin $10 \mathrm{mg} / \mathrm{sqm}$ was added shortly after completion of cytarabine infusion on days 1, 3 and 5 (FLAI) [14]. All patients achieving hematological complete remission (CR) after FLAI received the second induction, which included highdose cytarabine ( $2000 \mathrm{mg} / \mathrm{sqm}$ ) on days 1 to 5 , with the addition of an increased dose of idarubicin (12 $\mathrm{mg} / \mathrm{sqm}$ ) infused in $1 \mathrm{~h}$ on days 1,3 and 5 (Ara-C + Ida) [14].

Consolidation chemotherapy included up to 3 cycles of high dose cytarabine (2000 mg/sqm in a 4-h infusion once daily on day 1 to 4, HDAC) [14].

HSCT consolidation in first CR was planned according to risk score at diagnosis, donor availability and comorbidities (see Appendix B for further details). Consolidation chemotherapy with HDAC was given until transplantation to all patients who were considered eligible for HSCT in CR1 but for any reason could not immediately proceed to transplant.

\subsection{Response Assessment}

Conventional IWG definitions were adopted for response assessment [4]. Complete Response (CR) required a blast count on bone marrow lower than $5 \%$ alongside a complete hematological recovery, defined by normal neutrophil and platelet count. Complete Response with incomplete recovery (CRi) was defined when the bone marrow criteria for CR were met but complete hematologic recovery was not achieved. Partial Response (PR) required a reduction in bone marrow blast cells higher than $50 \%$ from diagnosis, with an absolute blast count lower than $25 \%$, without fulfilling CR or CRi criteria [4]. Bone marrow aspirate for response assessment was performed in each center as per local clinical standards. NPM1-based, MRD-negative CR was defined as previously described [20-22].

\subsection{Statistical Analysis}

Chi-Square test and Fisher's exact were applied in order to compare dichotomous variables, whereas continuous variables were compared using Student's $t$-test or Wilcoxon's rank test, if normal distribution could not be confirmed. For multivariate analysis, a logistic regression model was built, including only variables with a $p$ value lower than 0.100 in early univariate analysis [24].

A competing risk analysis model was built for the calculation of cumulative incidence of relapse, accounting non-relapse mortality (NRM) as a competing event. A Fine and Gray sub-distribution relative hazard method was applied for competing risk analysis, and Gray's test was adopted for comparison. Overall Survival (OS) was calculated from the first day of induction treatment until death by any cause or until last follow-up. In order to assess the impact of transplantation in first complete remission, we built a separate landmark analysis, including only patients who were alive and still in CR at day 90 . The Log-rank test was used for univariate survival analysis and all survival curves were built using the Kaplan-Meier method. Each multivariate survival analysis was performed with a Cox Proportional Hazard Model, including only variables respecting the proportional risk assumption [24]. Proportional risk assumption was checked for all variables plotting scaled Schönfeld residuals against time.

All statistical analysis, with the exception of competing risk analysis and proportional hazard assumption confirmation, were performed with IBM SPSS v22@ for Linux, whereas competing risk analysis and proportional hazard assumption confirmation was performed using R statistical software (www.r-project.com) for Linux.

\section{Results}

\subsection{Patients}

One-hundred and forty-nine consecutive AML patients, with NPM1, FLT3-ITD mutation or both, treated in three Hematology Italian centers from January 2008 to January 
2018, were retrospectively included in this analysis. Twenty-nine patients had isolated FLT3-ITD (19.5\%), 59 concomitant FLT3-ITD and NPM1 mut (39.6\%) and 61 isolated NPM1 mut $(40.9 \%)$. ELN 2017 risk score was low in $56(37.6 \%)$, intermediate in $51(34.2 \%)$ and high in $42(28.2 \%)$. Median age was 52 years (range: 18-65). All patients received the same intensified induction and consolidation. After a median of 92 days (range 84-115), 35 patients received HSCT in CR1; among them, 6, 15 and 14 were considered low, intermediate or high risk, respectively, according to ELN 2017. Patients' characteristics are summarized in Table 1.

Table 1. Patients' features.

\begin{tabular}{ccc}
\hline \multicolumn{2}{c}{ Patients' Features } & Num. (\%) \\
\hline OVERALL & & $149(100 \%)$ \\
\hline \multirow{2}{*}{ Age } & $<45$ years & $52(34.9 \%)$ \\
& $>45$ years & $97(65.1 \%)$ \\
Sex & Male & $84(56.4 \%)$ \\
& Female & $65(43.6 \%)$ \\
Neukocytes & $<30,000 / \mu \mathrm{L}$ & $64(43 \%)$ \\
& $>30,000 / \mu \mathrm{L}$ & $85(57 \%)$ \\
FLT3-ITD & Mutated & $120(80.5 \%)$ \\
& Unmutated & $29(19.5 \%)$ \\
Karyotype & Negative & $61(40.9 \%)$ \\
& Positive & $88(59.1 \%)$ \\
ELN ${ }^{1} 2017$ & Intermediate & $133(89.3 \%)$ \\
& Unfavorable & $16(10.7 \%)$ \\
& Low Risk & $56(37.6 \%)$ \\
NPM1/FLT3-ITD & Intermediate Risk & $51(34.2 \%)$ \\
& High Risk & $42(28.2 \%)$ \\
& $N P M 1$ mut/FLT3-ITD neg & $61(40.9 \%)$ \\
& $N P M 1$ mut/FLT3-ITD pos & $59(39.6 \%)$ \\
& $N P M 1$ wt/FLT3-ITD pos & $29(19.5 \%)$ \\
\hline
\end{tabular}

\footnotetext{
${ }^{1}$ ELN $=$ European Leukemia Net.
}

\subsection{Response and Toxicities}

After the first induction cycle, CR was achieved in $129 / 149$ patients $(86.6 \%)$, whereas $13 / 149$ patients did not fulfill the CR criteria $(8.7 \%)$. Sixty-day treatment-related mortality was $7 / 149(4.7 \%)$, mainly due to uncontrolled bleeding $(n=3)$ or infections $(n=4)$. Overall, the vast majority of patients was able to fully receive the pre-planned dosage of induction and consolidation courses. Extra-hematological toxicity was negligible as previously reported (14).

CR rate was significantly higher in NPM1 mut if compared to NPM1 wt patients (90.6\% and $72.4 \%$, respectively, $p<0.02$, Table 2$)$. A trend towards a reduced CR rate was observed according to FLT3-ITD mutation (CR rate $93.4 \%$ and $81.8 \%$, for FLT3-ITD-negative or -positive patients, respectively, $p=0.051$, Table 2). Patients with low or high FLT3-ITD allelic burden had a similar response probability (CR rate $80.2 \%$ and $82.4 \%$ for patients with high or low allelic burden, $p=0.875$ ).

Response rate was higher among isolated NPM1 mut patients, if compared to patients with either co-mutated or isolated FLT3-ITD (CR rate $93.4 \%, 86.4 \%$ and $72.4 \%$, respectively, $p<0.03$, Table 2).

None of the other analyzed variables significantly impacted the CR rate.

In multivariate logistical regression analysis, NPM1 status was the only independent predictor of response $(p<0.05$, Table 2$)$.

NPM MRD assessment was available in $63 / 129 \mathrm{CR}$ patients (48.8\%). After induction, $37 / 63$ (58.7\%) patients had NPM MRD-negative CR with no difference between NPM1 mut patients with or without concomitant FLT3 ITD (19/32, 59.4\% and 18/31, 58.1\%, respectively, $p=0.916)$, regardless of FLT3 ITD allelic burden $(11 / 18,61.1 \%$ and $8 / 14,57.1 \%$ 
among NPM1 mut/FLT3-ITD-positive patients, with high or low FLT3-ITD allelic burden, respectively, $p=0.821$ ).

Table 2. Complete Response (CR) probability.

\begin{tabular}{|c|c|c|c|c|c|}
\hline \multicolumn{2}{|c|}{ Patients' Features } & \multirow{2}{*}{$\begin{array}{c}\text { Num. } \\
149\end{array}$} & \multirow{2}{*}{$\begin{array}{c}\text { CR (\%) } \\
129(86.6)\end{array}$} & \multirow{2}{*}{$\begin{array}{c}p \\
\text { (univ.) } \\
-\end{array}$} & \multirow{2}{*}{$\begin{array}{c}\begin{array}{c}p \\
\text { (multiv.) }\end{array} \\
-\end{array}$} \\
\hline OVERALL & & & & & \\
\hline Age & $<45$ years & $\begin{array}{l}52 \\
97\end{array}$ & $47(90.4)$ & 0.318 & - \\
\hline Sex & $\begin{array}{l}\text { Male } \\
\text { Female }\end{array}$ & $\begin{array}{l}84 \\
65\end{array}$ & $\begin{array}{l}73(86.9) \\
56(86.2)\end{array}$ & 1.000 & - \\
\hline Leukocytes & $\begin{array}{l}<30,000 / \mu \mathrm{L} \\
>30,000 / \mu \mathrm{L}\end{array}$ & $\begin{array}{l}64 \\
85\end{array}$ & $\begin{array}{l}58(90.6) \\
71(83.5)\end{array}$ & 0.209 & - \\
\hline NPM1 & $\begin{array}{l}\text { Mutated } \\
\text { Unmutated }\end{array}$ & $\begin{array}{l}120 \\
29\end{array}$ & $\begin{array}{l}108(90.0) \\
21(72.4)\end{array}$ & 0.019 & 0.012 \\
\hline FLT3-ITD & $\begin{array}{l}\text { Negative } \\
\text { Positive }\end{array}$ & $\begin{array}{l}61 \\
88\end{array}$ & $\begin{array}{l}57(93.4) \\
72(81.8)\end{array}$ & 0.051 & 0.255 \\
\hline Karyotype & $\begin{array}{l}\text { Intermediate } \\
\text { Unfavorable } \\
\text { Low Risk }\end{array}$ & $\begin{array}{l}133 \\
16 \\
56\end{array}$ & $\begin{array}{l}115(86.5) \\
14(84.5) \\
53(94.6)\end{array}$ & 1.000 & - \\
\hline ELN $^{1} 2017$ & $\begin{array}{c}\text { Intermediate Risk } \\
\text { High Risk }\end{array}$ & $\begin{array}{l}51 \\
42\end{array}$ & $\begin{array}{l}43(84.3) \\
33(78.6)\end{array}$ & 0.059 & 0.545 \\
\hline NPM1/FLT3-ITD & $\begin{array}{l}\text { NPM1 mut/FLT3-ITD neg } \\
\text { NPM1 mut/FLT3-ITD pos } \\
\text { NPM1 wt/FLT3-ITD pos }\end{array}$ & $\begin{array}{l}61 \\
59 \\
29\end{array}$ & $\begin{array}{l}57(93.4) \\
51(86.4) \\
21(72.4)\end{array}$ & 0.024 & - \\
\hline
\end{tabular}

${ }^{1}$ ELN $=$ European Leukemia Net.

\subsection{Relapse and Cumulative Incidence of Relapse}

After a median follow-up of 68 months (CI 95\%: 55.87-80.13 months), 32 patients relapsed $(24.8 \%)$.

Relapse probability was higher among patients without NPM1 mutation $(p<0.01)$ and among high-risk patients according to ELN $2017(p<0.03)$. Multi-variate analysis confirmed that NPM1 mutational status was the only predictor of relapse probability $(p<0.05)$. Relapse probability analysis is detailed in Table 3.

Table 3. Relapse probability.

\begin{tabular}{|c|c|c|c|c|c|}
\hline \multicolumn{2}{|c|}{ Patients' Features } & \multirow{2}{*}{$\begin{array}{c}\text { Num. } \\
129\end{array}$} & \multirow{2}{*}{$\begin{array}{c}\begin{array}{c}\text { Relapse } \\
\text { (\%) }\end{array} \\
32(24.8)\end{array}$} & \multirow{2}{*}{$\begin{array}{c}\begin{array}{c}p \\
\text { (univ.) }\end{array} \\
-\end{array}$} & \multirow{2}{*}{$\frac{\begin{array}{c}p \\
\text { (multiv.) }\end{array}}{-}$} \\
\hline OVERALL & & & & & \\
\hline \multirow{2}{*}{ Age } & $<45$ years & 47 & $9(19.1)$ & \multirow{2}{*}{1.000} & \multirow{2}{*}{-} \\
\hline & $>45$ years & 82 & $23(28.0)$ & & \\
\hline \multirow{2}{*}{ Sex } & Male & 73 & $22(30.1)$ & \multirow{2}{*}{0.109} & \multirow{2}{*}{-} \\
\hline & Female & 56 & $10(17.9)$ & & \\
\hline \multirow{2}{*}{ Leukocytes } & $<30,000 / \mu \mathrm{L}$ & 58 & $14(24.1)$ & \multirow{2}{*}{0.296} & \multirow{2}{*}{-} \\
\hline & $>30,000 / \mu \mathrm{L}$ & 71 & $18(25.4)$ & & \\
\hline \multirow{2}{*}{ NPM1 } & Mutated & 108 & $23(21.3)$ & \multirow{2}{*}{0.009} & \multirow{2}{*}{0.03} \\
\hline & Unmutated & 21 & $9(42.9)$ & & \\
\hline \multirow{2}{*}{ FLT3-ITD } & Negative & 57 & $10(17.5)$ & \multirow{2}{*}{0.104} & \multirow{2}{*}{-} \\
\hline & Positive & 72 & $22(30.6)$ & & \\
\hline \multirow{3}{*}{ Karyotype } & Intermediate & 115 & $27(23.5)$ & \multirow{3}{*}{0.317} & \multirow{3}{*}{-} \\
\hline & Unfavorable & 14 & $5(35.7)$ & & \\
\hline & Low Risk & 53 & $7(13.2)$ & & \\
\hline \multirow[t]{3}{*}{ ELN $^{1} 2017$} & Intermediate Risk & 43 & $9(20.9)$ & \multirow[t]{3}{*}{0.01} & \multirow[t]{3}{*}{0.494} \\
\hline & High Risk & 33 & $16(48.5)$ & & \\
\hline & NPM1 mut/FLT3-ITD neg & 57 & $10(17.5)$ & & \\
\hline \multirow[t]{2}{*}{ NPM1/FLT3-ITD } & NPM1 mut/FLT3-ITD pos & 51 & $13(25.5)$ & \multirow[t]{2}{*}{0.071} & \multirow[t]{2}{*}{-} \\
\hline & NPM1 wt/FLT3-ITD pos & 21 & $9(42.9)$ & & \\
\hline
\end{tabular}

\footnotetext{
${ }^{1}$ ELN = European Leukemia Net.
} 
In competing risk analysis, 3-years cumulative incidence of relapse (CIR) was $23.6 \%$ (Figure S1).

CIR was not significantly different among NPM1 mutated with or without concomitant FLT3-ITD (3-year CIR 23.8\% and 19.1\%, respectively, $p=0.698$ ), irrespectively of allelic burden (data not shown), whereas patients with isolated FLT3-ITD had a significantly higher CIR (3-year CIR 42.7\%, $p<0.05$ ).

\subsection{Overall Survival}

In the whole cohort, $63 / 149$ (42.3\%) patients died, and 3-year OS was 58.6\% (median not reached, Figure 1A).
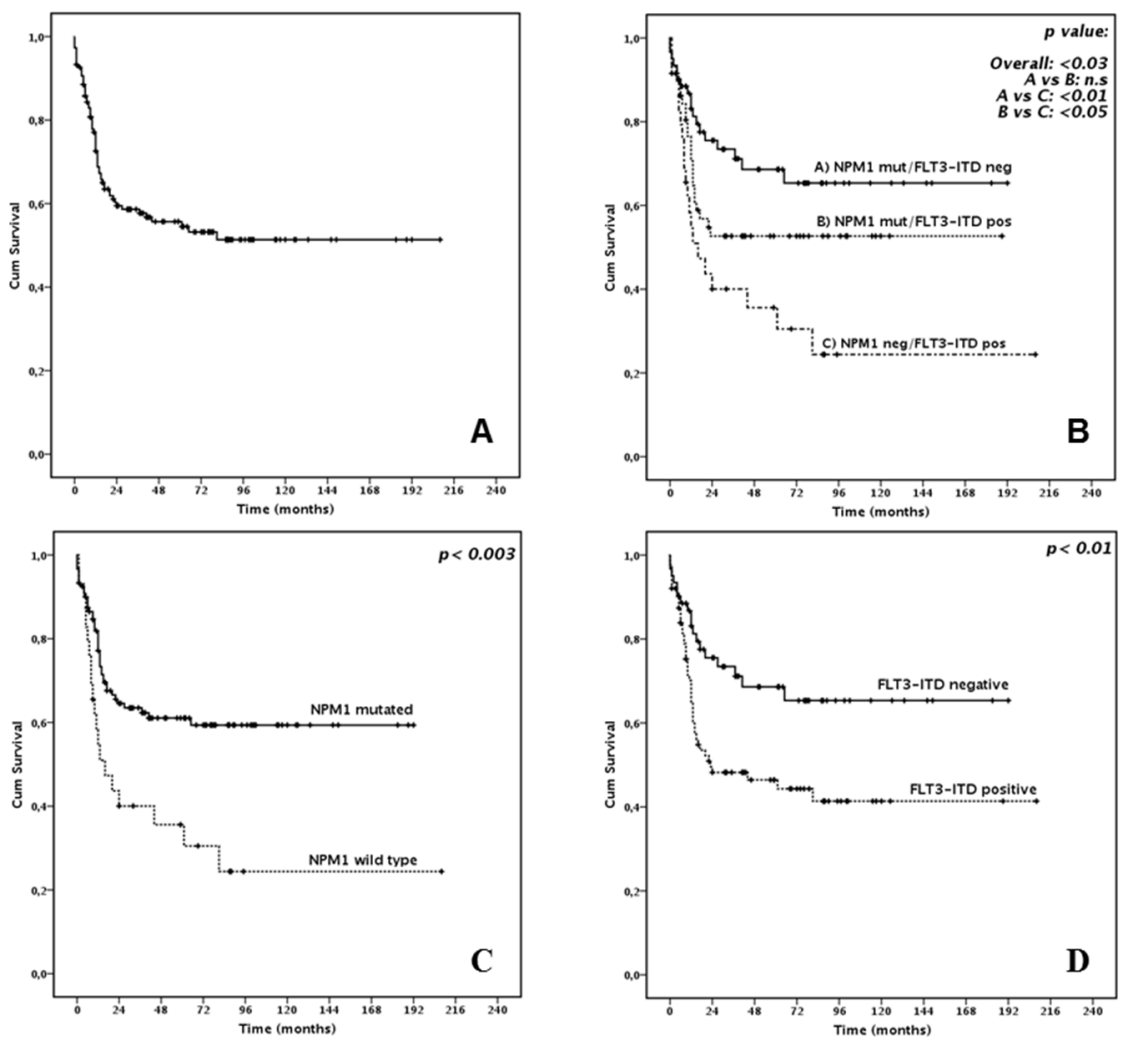

Figure 1. Overall Survival: (A) In the whole cohort (B) According to NPM1/FLT3-ITD status (C) According to NPM1 status (D) According to FLT3-ITD status.

In univariate analysis, high leukocyte count at diagnosis $(p<0.05)$ the absence of NPM1 mutation ( $p<0.003$, Figure 1C), presence of FLT3-ITD ( $p<0.01$, Figure 1D) and high risk according to ELN 2017 ( $p<0.0001$, Figure S2) were correlated with significantly worse survival. Concerning FLT3-ITD and NPM1 reciprocal mutational status, the presence of FLT3-ITD did not significantly affect survival among NPM1 mut patients (3-year OS 52.7 and $73.4 \%$, for NPM1-mutated patients with or without concomitant FLT3-ITD, $p=0.372$, Figure 1B). This observation was more evident among patients aged 55 or less, where the outcome of NPM1 mut patients, with or without concomitant FLT3-ITD, was almost completely superimposable ( $p=0.924$, Figure 2$)$. The implementation of allelic burden assessment did not significantly modify those findings: 3 -year OS was $71.8 \%$ and $74.1 \%$ in NPM1-mutated patients with or without concomitant low-burden FLT3-ITD ( $p=0.758)$, which was not significantly different from what was observed among NPM1-mutated patients with concomitant high-burden FLT3-ITD (3-year OS 61.4\%, $p=0.187$ ). 


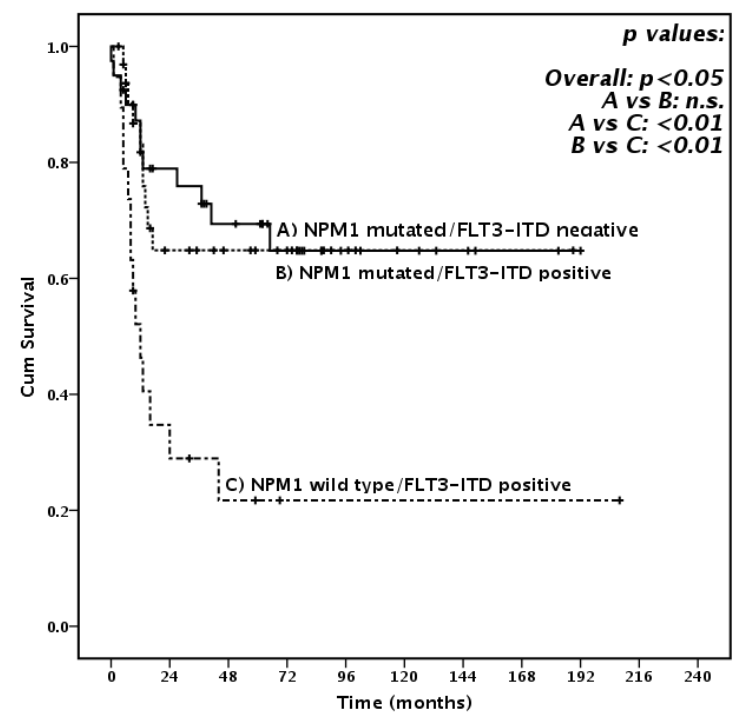

Figure 2. Overall Survival in patients aged 55 or less according to NPM1 and FLT3-ITD status.

FLT3-ITD isolated patients had a significantly worse prognosis $(p<0.05)$. Multivariate analysis disclosed that both NPM1 mutational status and ELN 2017 risk score were significant predictors of survival ( $p<0.05$ and $p<0.05$, respectively). Detailed OS analysis is provided in Table 4.

Table 4. Overall survival analysis and landmark analysis.

\begin{tabular}{|c|c|c|c|c|c|c|}
\hline \multicolumn{2}{|c|}{ Patients' Features } & Dead $(\%)$ & $\begin{array}{c}\text { 3-Year OS } \\
(\%)\end{array}$ & $\begin{array}{c}\text { Median OS } \\
(\%)\end{array}$ & $p$ (univ.) & $\begin{array}{c}p \\
\text { (multiv.) }\end{array}$ \\
\hline \multicolumn{2}{|l|}{ OVERALL } & $63(42.3)$ & 58.6 & NR & - & - \\
\hline \multirow{2}{*}{ Age } & $<45$ years & $17(32.7)$ & 65.4 & NR & \multirow{2}{*}{0.086} & \multirow{2}{*}{-} \\
\hline & $>45$ years & $46(47.4)$ & 55.2 & 65 & & \\
\hline \multirow{2}{*}{ Sex } & Male & $41(48.8)$ & 53.8 & 44 & \multirow{2}{*}{0.108} & \multirow{2}{*}{-} \\
\hline & Female & $22(33.8)$ & 65.0 & NR & & \\
\hline \multirow{2}{*}{ Leukocytes } & $<30,000 / \mu \mathrm{L}$ & $22(34.4)$ & 73.2 & NR & \multirow[b]{2}{*}{0.034} & \multirow[b]{2}{*}{0.569} \\
\hline & $>30,000 / \mu \mathrm{L}$ & $44(48.2)$ & 47.5 & 23 & & \\
\hline \multirow{2}{*}{ NPM1 } & Mutated & $43(35.8)$ & 63.5 & NR & \multirow{2}{*}{0.002} & \multirow{2}{*}{0.034} \\
\hline & Unmutated & $20(69.0)$ & 40.0 & 16 & & \\
\hline \multirow{2}{*}{ FLT3-ITD } & Negative & $18(29.5)$ & 73.4 & NR & \multirow[b]{2}{*}{0.006} & \multirow[b]{2}{*}{0.178} \\
\hline & Positive & $45(51.1)$ & 48.2 & 23 & & \\
\hline \multirow{2}{*}{ Karyotype } & Intermediate & $54(40.6)$ & 59.1 & NR & \multirow[b]{2}{*}{0.550} & \multirow{2}{*}{-} \\
\hline & Unfavorable & $9(56.2)$ & 55.6 & 44 & & \\
\hline \multirow{3}{*}{ ELN $^{1} 2017$} & Low Risk & $14(25.0)$ & 77.0 & NR & \multirow{3}{*}{0.000} & \multirow{3}{*}{0.048} \\
\hline & Intermediate Risk & $19(37.3)$ & 58.5 & NR & & \\
\hline & High Risk & $30(71.4)$ & 35.2 & 13 & & \\
\hline \multirow{3}{*}{ NPM1/FLT3-ITD } & NPM1 mut/FLT3-ITD neg & $18(29.5)$ & 73.4 & NR & \multirow{3}{*}{0.002} & \multirow{3}{*}{-} \\
\hline & NPM1 mut/FLT3-ITD pos & $25(42.4)$ & 52.7 & NR & & \\
\hline & NPM1 wt/FLT3-ITD pos & $20(69.0)$ & 40.0 & 16 & & \\
\hline \multicolumn{2}{|c|}{ LANDMARK SURVIVAL ANALYSIS } & $\begin{array}{c}45 / 129 \\
(34.9) \\
\end{array}$ & 63.6 & NR & & \\
\hline \multirow{2}{*}{ All patients } & HSCT in first CR & $15 / 35(42.9)$ & 58.7 & 81 & \multirow{2}{*}{0.348} & \multirow{2}{*}{-} \\
\hline & No HSCT in first CR & $30 / 94(32.9)$ & 68.9 & NR & & \\
\hline \multirow{2}{*}{ NPM1 mutated } & HSCT in first CR & $8 / 25(32)$ & 62.5 & NR & & \\
\hline & No HSCT in first CR & $23 / 83(37.7)$ & 73.5 & NR & 0.625 & - \\
\hline & HSCT in first CR & $13 / 28(46.4)$ & 56.7 & 81 & & \\
\hline FLT3-ITD & No HSCT in first CR & $18 / 44(40.9)$ & 55.6 & NR & 0.970 & - \\
\hline ELN $^{1}$ 2017High & HSCT in first CR & $9 / 14(64.3)$ & 50 & 24 & & - \\
\hline Risk & No HSCT in first CR & $14 / 19(73.7)$ & 27.1 & 13 & 0.044 & - \\
\hline
\end{tabular}


Landmark analysis showed that in the whole cohort patients undergoing or not HSCT in first CR did not show significantly different survival (3-year OS 58.7\% and 68.9\%, median 81 months and not reached, respectively, $p=0.348$, Figure 3A).
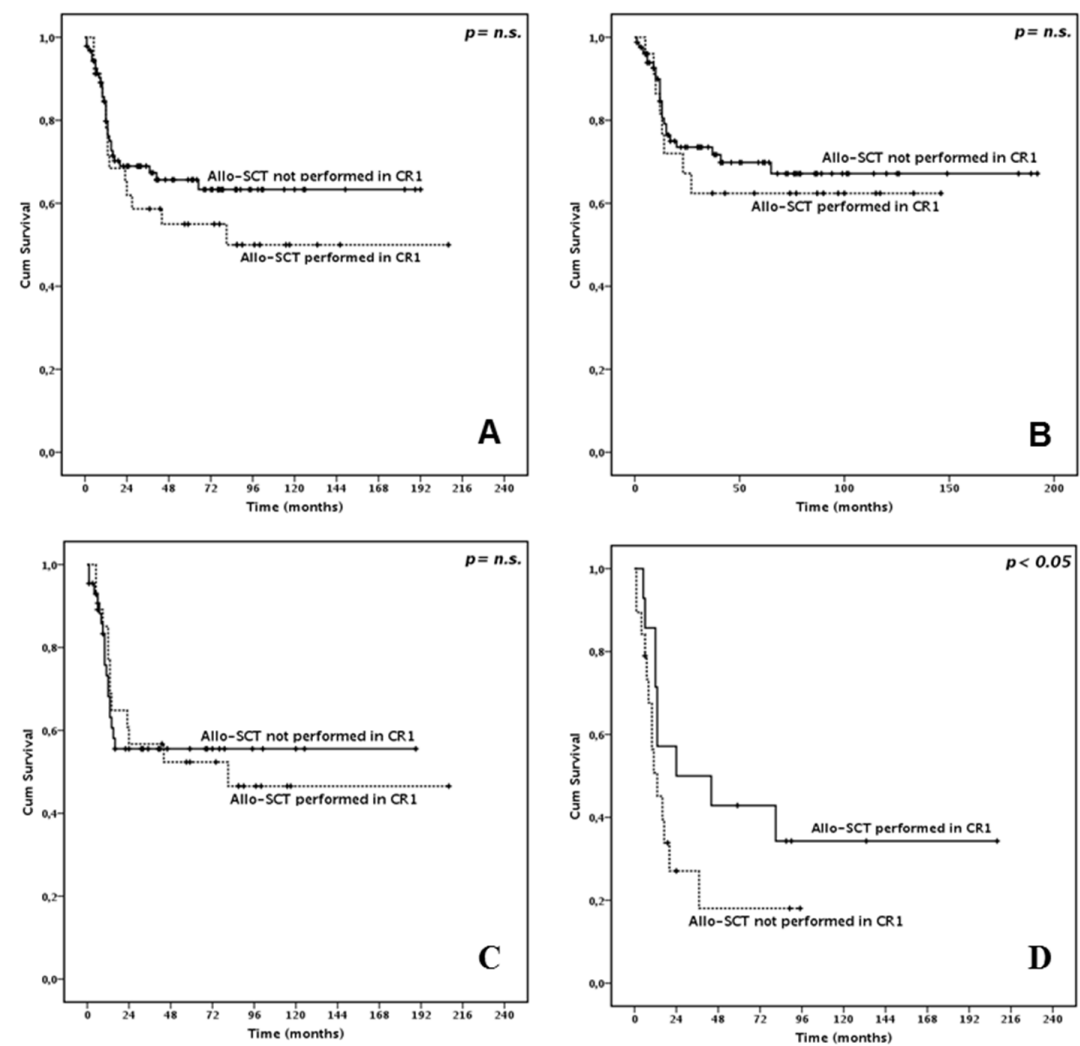

Figure 3. Overall Survival according to performing or not allogeneic stem cell transplantation (SCT) in first complete remission (CR1) (Landmark analysis). (A) In the whole cohort (B) In NPM1 mutated patients (C) In FLT3-ITD positive patients (D) In European LeukemiaNet 2017 high risk patients.

Subgroup sub-analysis showed that performing HSCT in first CR did not result in better survival in patients with NPM1 mutations and in patients with FLT3-ITD ( $p=0.625$ and 0.970, respectively, Figure 3B-C). Conversely, HSCT was beneficial for ELN 2017 highrisk patients $(p<0.05$, Figure 3D). Further details on landmark analysis are provided in Table 4.

\section{Discussion}

In our multi-centric, real-life study including younger AML patients homogeneously treated with FLAI regimen, NPM1 mut patients had a very good long-term outcome and concomitant FLT3-ITD mutation did not impact on survival, regardless of allelic burden. The outcome of NPM1 mut AML patients seems to be at least comparable with, if not better than, that reported with conventional 3+7 regimen [7-9] with or without the addition of GO [11]. One possible biological explanation for the high activity of FLAI in this setting may be the higher chemo sensitivity conferred by the NPM1 mutation. Indeed, it has been demonstrated that the cytoplasmic delocalization of NPM1, determined by the NPM1 mutation, induces the reduction in the anti-apoptotic activity of NPM1 protein and increased genomic instability $[25,26]$. The increased NPM1-related chemo-sensitivity and the higher intracellular cytarabine concentration following fludarabine administration may overcome the survival advantage conferred to blast cells by FLT3-ITD mutation $[9,25-28]$. This biological explanation is supported by the observation that the rate of NPM-MRD negative CR was not affected by concomitant FLT3-ITD, regardless of allelic burden. 
Moreover, the crucial role of increased chemo-sensitivity, related to NPM1 mutation, may be further sustained by the better outcome achieved in patients $<55$ years, where dose intensity and timing of treatment are more likely to be respected. In this age group, the survival of patients belonging to low- and intermediate ELN risk groups was, in fact, superimposable.

The retrospective nature of our study prevents us from drawing any firm conclusion from the analysis of this subset of patients and limits any comparison with prospective, randomized trials. However, some interesting results deserve to be discussed. In the recent midostaurin phase III trial, the survival advantage due to the addition of midostaurin to chemotherapy was not statistically significant when patients were censored at transplantation, thus suggesting an important therapeutic role for HSCT in first CR [10].

In a Spanish trial reporting the outcome of patients receiving intermediate-dose cytarabine-containing regimens, Pratcorona et al. showed that HSCT in first CR was not beneficial in term of relapse risk and survival for NPM1 mutated with concomitant lowburden FLT3-ITD. An advantage for early transplantation was, however, evident among high-burden FLT3-ITD, regardless of NPM1 status [29].

Our study confirms the good outcome achieved without frontline HSCT in the favorable group of NPM1 mut/low-burden FLT3-ITD patients. With the limitation of a retrospective study, our results suggest that the FLAI regimen may reduce the need for early HSCT consolidation in the whole group of non-high-risk patients, which includes NPM1 mut/high-burden FLT3-ITD patients. In this view, MRD assessment may help in identifying non-high-risk patients with suboptimal response to first induction who may benefit from early HSCT $[20,22]$. Furthermore, in NPM-mut patients, the highly sensitive PCR-based MRD evaluation is able to identify patients still in hematologic CR but with molecular relapse, thus allowing preemptive strategies of salvage therapy and subsequent HSCT consolidation [21,30]. Additionally, for patients harboring FLT3 mutations, the recently approved, highly selective, second-generation FLT3 inhibitors may represent an optimal bridge to transplant approach for relapsing patients [31-33].

Conversely, our data confirm that HSCT in first CR is the best option for ELN 2017 high-risk patients, i.e., patients with isolated FLT3-ITD with high allelic burden or patients with other unfavorable molecular or cytogenetic alterations [4].

\section{Conclusions}

In conclusion, with the limitations of a retrospective study, FLAI-5 seems to be an effective therapy for NPM1 mut AML patients, regardless of FLT3-ITD status and may not require the application of HSCT in first CR, especially in patients achieving a rapid MRD clearance [22,29]. In AML patients with FLT3-ITD without NPM1 mutation, the addition of drugs targeting FLT3 [11,31-33], BCL2 [34] may be indicated. In this regard, given the very high CR rate and the good tolerability, FLAI may represent the optimal backbone for testing novel agents [15,35]. In this view, GIMEMA AML1718 trial (Eudract code 2018-000392-33) is currently evaluating FLAI plus venetoclax as induction regimen in intermediate/high-risk patients, including patients bearing FLT3 mutations.

Supplementary Materials: The following are available online at https: / www.mdpi.com/2072-6 694/13/1/34/s1, Figure S1: Cumulative Incidence of Relapse in all patients. Figure S2: Overall Survival in all patients according to ELN 2017.

Author Contributions: Conceptualization P.M., A.C., F.G., M.B., M.C. (Marino Clavio) and R.M.L.; methodology E.C., N.C., G.P., M.M., M.C. (Michele Cea) and M.G.; investigation P.M., A.C., M.C. (Marino Clavio), R.M. and L.L.; software, F.G. and E.C.; validation, M.M. and M.C. (Michele Cea); formal analysis, F.G., N.C., G.P. and R.M.; data curation F.G., M.E.Z., M.V.D., A.S. (Anna Sicuranza), S.C. and F.B.; writing — original draft preparation, P.M., F.G., M.C. (Marino Clavio) and A.C.; writingreview and editing, P.M., M.C. (Marino Clavio), M.E.Z., M.V.D., A.S. (Anna Sicuranza), S.C., R.M., A.S. (Adele Santoni), F.B., M.G. and M.C. (Michele Cea); supervision, M.B., M.G., R.F. and R.M.L.; project administration, P.M., A.C., M.B. and R.M.L. All authors have read and agreed to the published version of the manuscript. 
Funding: This research received no external funding.

Institutional Review Board Statement: Ethical review and approval were waived for this study, due to the retrospective nature of this study.

Informed Consent Statement: Informed consent was obtained from all subjects involved in the study. Data Availability Statement: Data available on request due to restrictions eg privacy or ethical.

Conflicts of Interest: The authors declare no conflict of interest.

\section{Appendix A}

Citogenetic Analysis

A Q-banded chromosome study was performed on diagnostic BM samples using standard cytogenetic techniques. Karyotyping was carried out on QFQ-banded chromosomes and was reported using the ISCN-1995 nomenclature after analysing a minimum of 20 metaphases for samples with no clonal aberrations. The prognostic significance of karyotypic findings was defined according to the MRC criteria [3].

\section{Molecular Analysis}

NPM1 mutation (NPM1-A, B and D mutation) was measured using Muta Quant Kit Ipsogen from Qiagen [36]. FLT3-ITD allelic burden was determined as ratio of Time PCR were performed on DNA Engine Opticon 2-BIORAD.

FLT3-ITD mutations were searched using polymerase chain reaction (PCR the area under the curve "FLT3-ITD" divided by AUC "FLT3-wild type" (low allelic ratio < 0.5; high allelic ratio > 0.5) [8,37].

Biallellic CEBPa were detected by genomic DNA PCR and direct sequencing. The primer sets are those designed by Pabst et al. [38]. There are three overlapping primer pairs that were used to amplify the entire coding region of human $C E B P a$ : $C E B P a \mathrm{AF}-$ TCGCCATGCCGGGAGAACTCTAAC, CEBPa ARAGCTGCTTGGCTTCATCCTCCT (548bp); CEBPa BF-CCGCTGGTGATCAAGCAGGA, CEBPa BR-CCGGTACTCGTTGCTGTT CT (390bp); CEBPa CFCAAGGCCAAGAAGTCGGTGGACA, CEBPa CR-CACGGTCTGGG CAAGCCTCGAGAT (356bp).

PCR reactions were made in a final volume of $50 \mu \mathrm{L}$ containing genomic DNA (300 ng), $\mathrm{KCl}$ (50 mmol/L), Tris-HCl (20 mmol/L, pH 8.4), $\mathrm{MgCl}_{2}$ (2.5 mmol/L), 5 vol.\% DMSO, primers $(2 \mathrm{mmol} / \mathrm{L}$ of each), nucleotides $(0.1 \mathrm{mmol} / \mathrm{L}$ of each), and Taq DNA polymerase (1U). PCR conditions were $94{ }^{\circ} \mathrm{C}$ for $45 \mathrm{~s}, 62^{\circ} \mathrm{C}$ for $45 \mathrm{~s}$ and $72{ }^{\circ} \mathrm{C}$ for $45 \mathrm{~s}$ for 45 cycles, with a final step for $10 \mathrm{~min}$ at $72{ }^{\circ} \mathrm{C}$. PCR products were sequenced using BigDye. Terminator Cycle Sequencing Kit o v1.1 kit (Applied Biosystems) on ABI 3730 Genetic Analyzer (Applied Biosystems).

The other, rarer mutations required for ELN 2017 risk assessment (RUNX1, TP53, ASXL-1) were performed as recommended [4].

\section{Appendix B}

\section{Risk Stratification and Allogeneic Stem Cell Transplantation}

Risk assessment at diagnosis for allocation to HSCT in first remission was based on ELN 2010 risk score [39] for patients treated before 2017, and according to ELN 2017 for patients treated after 2017 [4].

Patients considered at high risk were scheduled for HSCT in first remission from any donor as soon as a CR was achieved.

The indication for HSCT in first CR for intermediate risk patients was based on the availability of a familiar matched donor, patient age and transplantation risk, defined according to Sorror et al [40].

Favourable risk patients were not considered eligible for HSCT in first remission. Indeed, due to the retrospective nature of the study, as ELN 2017 classification was retrospectively applied, some patients included in theintermediate risk group according to ELN 2010, have been re-classified with the newer classification (e.g., patients with 
NPM1 mut/FLT3-ITD low, biallelic CEBPa mutation retrospectively found in an NPM1unmutated/FLT3-ITD patient). Similarly, some patients included in the intermediateand high-risk groups according to ELN 2010 were reclassified in a higher or lower risk group (e.g., TP53 or other high-risk mutations found in a ELN 2010 non-high-risk patient; NPM1-unmutated/FLT3-ITD-low patients)

The conditioning regimen and stem cell source was chosen by each centre according to the local practice.

\section{References}

1. Papaemmanuil, E.; Gerstung, M.; Bullinger, L.; Gaidzik, V.I.; Paschka, P.; Roberts, N.D.; Potter, N.E.; Heuser, M.; Thol, F.; Bolli, N.; et al. Genomic Classification and Prognosis in Acute Myeloid Leukemia. N. Engl. J. Med. 2016, 374, 2209-2221. [CrossRef]

2. Grimwade, D.; Ivey, A.; Huntly, B.J. Molecular landscape of acute myeloid leukemia in younger adults and its clinical relevance. Blood 2016, 127, 29-41. [CrossRef]

3. Grimwade, D.; Hills, R.K.; Moorman, A.V.; Walker, H.; Chatters, S.; Goldstone, A.H.; Wheatley, K.; Harrison, C.J.; Burnett, A.K. National Cancer Research Institute Adult Leukaemia Working Group. Refinement of cytogenetic classification in acute myeloid leukemia: Determination of prognostic significance of rare recurring chromosomal abnormalities among 5876 younger adult patients treated in the United Kingdom Medical Research Council trials. Blood 2010, 116, 354-365. [CrossRef]

4. Döhner, H.; Estey, E.; Grimwade, D.; Amadori, S.; Appelbaum, F.R.; Büchner, T.; Dombret, H.; Ebert, B.L.; Fenaux, P.; Larson, R.A.; et al. Diagnosis and management of AML in adults: 2017 ELN recommendations from an international expert panel. Blood 2017, 129, 424-447. [CrossRef]

5. Schlenk, R.F.; Döhner, K.; Krauter, J.; Fröhling, S.; Corbacioglu, A.; Bullinger, L.; Habdank, M.; Späth, D.; Morgan, M.; Benner, A.; et al. German-Austrian Acute Myeloid Leukemia Study Group. Mutations and treatment outcome in cytogenetically normal acute myeloid leukemia. N. Engl. J. Med. 2008, 358, 1909-1918. [CrossRef]

6. Gale, R.E.; Green, C.; Allen, C.; Mead, A.J.; Burnett, A.K.; Hills, R.K.; Linch, D.C. Medical Research Council Adult Leukaemia Working Party. The impact of FLT3 internal tandem duplication mutant level, number, size, and interaction with NPM1 mutations in a large cohort of young adult patients with acute myeloid leukemia. Blood 2008, 111, 2776-2784. [CrossRef]

7. Schnittger, S.; Bacher, U.; Kern, W.; Alpermann, T.; Haferlach, C.; Haferlach, T. Prognostic impact of FLT3-ITD load in NPM1 mutated acute myeloid leukemia. Leukemia 2011, 25, 1297-1304. [CrossRef]

8. Fröhling, S.; Schlenk, R.F.; Breitruck, J.; Benner, A.; Kreitmeier, S.; Tobis, K.; Döhner, H.; Döhner, K. AML Study Group Ulm. Acute myeloid leukemia. Prognostic significance of activating FLT3 mutations in younger adults (16 to 60 years) with acute myeloid leukemia and normal cytogenetics: A study of the AML Study Group Ulm. Blood 2002, 100, 4372-4380. [CrossRef]

9. Kayser, S.; Schlenk, R.F.; Londono, M.C.; Breitenbuecher, F.; Wittke, K.; Du, J.; Groner, S.; Späth, D.; Krauter, J.; Ganser, A.; et al. German-Austrian AML Study Group (AMLSG). Insertion of FLT3 internal tandem duplication in the tyrosine kinase domain-1 is associated with resistance to chemotherapy and inferior outcome. Blood 2009, 114, 2386-2392. [CrossRef]

10. Stone, R.M.; Mandrekar, S.J.; Sanford, B.L.; Laumann, K.; Geyer, S.; Bloomfield, C.D.; Thiede, C.; Prior, T.W.; Döhner, K.; Marcucci, G.; et al. Midostaurin plus Chemotherapy for Acute Myeloid Leukemia with a FLT3 Mutation. N. Engl. J. Med. 2017, 377, 454-464. [CrossRef]

11. Lambert, J.; Pautas, C.; Terré, C.; Raffoux, E.; Turlure, P.; Caillot, D.; Legrand, O.; Thomas, X.; Gardin, C.; Gogat-Marchant, K.; et al. Gemtuzumab ozogamicin for de novo acute myeloid leukemia: Final efficacy and safety updates from the open-label, phase III ALFA-0701 trial. Haematologica 2019, 104, 113-119. [CrossRef] [PubMed]

12. Philpott, N.; Mehta, J.; Treleaven, J.; Powles, R. Idarubicin, high-dose cytarabine and etoposide for remission induction in therapy-related acute myeloid leukemia. Leuk. Lymphoma 1994, 15, 127-130. [CrossRef] [PubMed]

13. Burnett, A.K.; Russell, N.H.; Hills, R.K.; Hunter, A.E.; Kjeldsen, L.; Yin, J.; Gibson, B.E.; Wheatley, K.; Milligan, D. Optimization of chemotherapy for younger patients with acute myeloid leukemia: Results of the medical research council AML15 trial. J. Clin. Oncol. 2013, 31, 3360-3368. [CrossRef] [PubMed]

14. Guolo, F.; Minetto, P.; Clavio, M.; Miglino, M.; Di Grazia, C.; Ballerini, F.; Pastori, G.; Guardo, D.; Colombo, N.; Kunkl, A.; et al. High feasibility and antileukemic efficacy of fludarabine, cytarabine, and idarubicin (FLAI) induction followed by risk-oriented consolidation: A critical review of a 10-year, single-center experience in younger, non M3 AML patients. Am. J. Hematol. 2016, 91, 755-762. [CrossRef] [PubMed]

15. Russo, D.; Malagola, M.; de Vivo, A.; Fiacchini, M.; Martinelli, G.; Piccaluga, P.P.; Damiani, D.; Candoni, A.; Michielutti, A.; Castelli, M.; et al. Multicentre phase III trial on fludarabine, cytarabine (Ara-C), and idarubicin versus idarubicin, Ara-C and etoposide for induction treatment of younger, newly diagnosed acute myeloid leukaemia patients. Br. J. Haematol. 2005, 131, 172-179. [CrossRef] [PubMed]

16. Candoni, A.; Martinelli, G.; Toffoletti, E.; Chiarvesio, A.; Tiribelli, M.; Malagola, M.; Piccaluga, P.P.; Michelutti, A.; Simeone, E.; Damiani, D.; et al. Gemtuzumab-ozogamicin in combination with fludarabine, cytarabine, idarubicin (FLAI-GO) as induction therapy in CD33-positive AML patients younger than 65 years. Leuk. Res. 2008, 32, 1800-1808. [CrossRef]

17. Jain, P.; Kantarjian, H.M.; Ravandi, F.; Jabbour, E.; Daver, N.; Pemmaraju, N.; DiNardo, C.D.; Alvarado, Y.; Jain, N.; Borthakur, G.; et al. Cladribine Combined with Idarubicin and Ara-C (CLIA) As a Frontline and Salvage Treatment for Young Patients ( $\leq 65$ yrs) with Acute Myeloid Leukemia. Blood 2016, 128, 1639. [CrossRef] 
18. Seiter, K.; Ahmed, N.; Shaikh, A.; Baskind, P.; Liu, D. CLAG-based induction therapy in previously untreated high risk acute myeloid leukemia patients. Leuk. Res. 2016, 46, 74-78. [CrossRef]

19. Guolo, F.; Minetto, P.; Clavio, M.; Miglino, M.; Lemoli, R.M.; Gobbi, M. Intesive fludarabine-high dose cytarabine-idarubicin combination as induction therapy with risk-adapted consolidation may improve treatment efficacy in younger Acute Myeloid Leukemia (AML) patients: Rationales, evidences and future perspectives. BioSci. Trends 2017, 11, 110-114. [CrossRef]

20. Miglino, M.; Colombo, N.; Grasso, R.; Marani, C.; Clavio, M.; Pica, G.M.; Ballerini, F.; Ghiggi, C.; Minetto, P.; Guolo, F.; et al. Nucleophosmin gene-based monitoring in de novo cytogenetically normal acute myeloid leukemia with nucleophosmin gene mutations: Comparison with cytofluorimetric analysis and study of Wilms tumor gene 1 expression. Leuk. Lymphoma 2012, 53, 2214-2217. [CrossRef]

21. Guolo, F.; Minetto, P.; Clavio, M.; Miglino, M.; Colombo, N.; Cagnetta, A.; Cea, M.; Marcolin, R.; Todiere, A.; Ballerini, F.; et al Longitudinal minimal residual disease (MRD) evaluation in acute myeloid leukaemia with NPM1 mutation: From definition of molecular relapse to MRD-driven salvage approach. Br. J. Haematol. 2019, 186, e223-e225. [CrossRef]

22. Minetto, P.; Guolo, F.; Clavio, M.; Kunkl, A.; Colombo, N.; Carminati, E.; Fugazza, G.; Matarese, S.; Guardo, D.; Ballerini, F.; et al. Early minimal residual disease assessment after AML induction with fludarabine, cytarabine and idarubicin (FLAI) provides the most useful prognostic information. Br. J. Haematol. 2019, 184, 457-460. [CrossRef] [PubMed]

23. Krönke, J.; Schlenk, R.F.; Jensen, K.O.; Tschürtz, F.; Corbacioglu, A.; Gaidzik, V.I.; Paschka, P.; Onken, S.; Eiwen, K.; Habdank, M.; et al. Monitoring of minimal residual disease in NPM1 mutated acute myeloid leukemia: A study from the German-Austrian acute myeloid leukemia study group. J. Clin. Oncol. 2011, 29, 2709-2716. [CrossRef] [PubMed]

24. Delgado, J.; Pereira, A.; Villamor, N.; López-Guillermo, A.; Rozman, C. Survival analysis in hematologic malignancies: Recommendations for clinicians. Haematologica 2014, 99, 1410-1420. [CrossRef] [PubMed]

25. Falini, B.; Nicoletti, I.; Martelli, M.F.; Mecucci, C. Acute myeloid leukemia carrying cytoplasmic/mutated nucleophosmin (NPMc+ AML): Biologic and clinical features. Blood 2007, 109, 874-885. [CrossRef] [PubMed]

26. Zhang, S.; Qin, F.; Yang, L.; Xian, J.; Zou, Q.; Jin, H.; Wang, L.; Zhang, L. Nucleophosmin Mutations Induce Chemosensitivity in THP-1 Leukemia Cells by Suppressing NF-кB Activity and Regulating Bax/Bcl-2 Expression. J. Cancer 2016, 7, $2270-2279$. [CrossRef] [PubMed]

27. Gandhi, V.; Estey, E.; Keating, M.J.; Plunkett, W. Fludarabine potentiates metabolism of cytarabine in patients with acute myelogenous leukemia during therapy. J. Clin. Oncol. 1993, 11, 116-124. [CrossRef] [PubMed]

28. Gandhi, V.M.; Estey, E.; Du, M.; Nowak, B.; Keating, M.J.; Plunkett, W. Modulation of the cellular metabolism of cytarabine and fludarabine by granulocyte-colony-stimulating factor during therapy of acute myelogenous leukemia. Clin. Cancer 1995, 1, 169-178.

29. Pratcorona, M.; Brunet, S.; Nomdedéu, J.; Ribera, J.M.; Tormo, M.; Duarte, R.; Escoda, L.; Guàrdia, R.; de Llano, M.P.Q.; Salamero, O.; et al. Grupo Cooperativo Para el Estudio y Tratamiento de las Leucemias Agudas Mieloblásticas. Favorable outcome of patients with acute myeloid leukemia harboring a low-allelic burden FLT3-ITD mutation and concomitant NPM1 mutation: Relevance to post-remission therapy. Blood 2013, 121, 2734-2738. [CrossRef]

30. Marani, C.; Clavio, M.; Grasso, R.; Colombo, N.; Guolo, F.; Kunkl, A.; Ballerini, F.; Giannoni, L.; Ghiggi, C.; Fugazza, G.; et al. Integrating post induction WT1 quantification and flow-cytometry results improves minimal residual disease stratification in acute myeloid leukemia. Leuk. Res. 2013, 37, 1606-1611. [CrossRef]

31. Perl, A.E.; Martinelli, G.; Cortes, J.E.; Neubauer, A.; Berman, E.; Paolini, S.; Montesinos, P.; Baer, M.R.; Larson, R.A.; Ustun, C.; et al. Gilteritinib or Chemotherapy for Relapsed or Refractory FLT3-Mutated AML. N. Engl. J. Med. 2019, 381, 1728-1740. [CrossRef]

32. Cortes, J.E.; Khaled, S.; Martinelli, G.; Perl, A.E.; Ganguly, S.; Russell, N.; Krämer, A.; Dombret, H.; Hogge, D.; Jonas, B.A.; et al. Quizartinib versus salvage chemotherapy in relapsed or refractory FLT3-ITD acute myeloid leukaemia (QuANTUM-R): A multicentre, randomised, controlled, open-label, phase 3 trial. Lancet Oncol. 2019, 20, 984-997. [CrossRef]

33. Fathi, A.T. Emergence of crenolanib for FLT3-mutant AML. Blood 2013, 122, 3547-3548. [CrossRef]

34. Pollyea, D.A.; Amaya, M.; Strati, P.; Konopleva, M.Y. Venetoclax for AML: Changing the treatment paradigm. Blood Adv. 2019, 3, 4326-4335. [CrossRef]

35. Candoni, A.; Papayannidis, C.; Martinelli, G.; Simeone, E.; Gottardi, M.; Iacobucci, I.; Gherlinzoni, F.; Visani, G.; Baccarani, M.; Fanin, R. Flai (fludarabine, cytarabine, idarubicin) plus low-dose Gemtuzumab Ozogamicin as induction therapy in CD33-positive AML: Final results and long term outcome of a phase II multicenter clinical trial. Am. J. Hematol. 2018, 93, 655-663. [CrossRef]

36. Gorello, P.; Cazzaniga, G.; Alberti, F.; Dell'Oro, M.G.; Gottardi, E.; Specchia, G.; Roti, G.; Rosati, R.; Martelli, M.F.; Diverio, D.; et al. Quantitative assessment of minimal residual disease in acute myeloid leukemia carrying nucleophosmin (NPM1) gene mutations. Leukemia 2006, 20, 1103-1108. [CrossRef]

37. Schlenk, R.F.; Kayser, S.; Bullinger, L.; Kobbe, G.; Casper, J.; Ringhoffer, M.; Held, G.; Brossart, P.; Lübbert, M.; Salih, H.R.; et al. Differential impact of allelic ratio and insertion site in FLT3-ITD-positive AML with respect to allogeneic transplantation. Blood 2014, 124, 3441-3449. [CrossRef]

38. Pabst, T.; Mueller, B.U.; Zhang, P.; Radomska, H.S.; Narravula, S.; Schnittger, S.; Behre, G.; Hiddemann, W.; Tenen, D.G. Dominantnegative mutations of CEBPA, encoding CCAAT/enhancer binding protein-alpha (C/EBPalpha), in acute myeloid leukemia. Nat. Gen. 2001, 27, 263-270. [CrossRef] 
39. Döhner, H.; Estey, E.H.; Amadori, S.; Appelbaum, F.R.; Büchner, T.; Burnett, A.K.; Dombret, H.; Fenaux, P.; Grimwade, D.; Larson, R.A.; et al. Diagnosis and management of acute myeloid leukemia in adults: Recommendations from an international expert panel, on behalf of the European Leukemia Net. Blood 2010, 115, 453-474. [CrossRef]

40. Sorror, M.L.; Maris, M.B.; Storb, R.; Baron, F.; Sandmaier, B.M.; Maloney, D.G.; Storer, B. Hematopoietic cell transplantation (HCT)-specific comorbidity index: A new tool for risk assessment before allogeneic HCT. Blood 2005, 106, 2912-2919. [CrossRef] 